\title{
articles
}

\section{Depression in Kraepelinian schizophrenia}

H E Naude, MB ChB, MMed (Psych), FCPsych (SA)

R Sykes, MB ChB, MMed (Psych) FCPsych (SA)

R R du Preez, MB ChB, MMed (Psych)

H W Pretorius, MSC, MB ChB, MMed (Psych),

MD, FC (Psych) (SA)

Department of Psychiatry, University of Pretoria

$M J$ van der Linde, $B S C, B S C$ (Hons), PhD, UED

J Pauw, BSC, BSC (Hons), MSC

Department of Statistics, University of Pretoria

Objective. Depressive symptoms are prevalent, underrecognised and clinically important in patients suffering from schizophrenia. Depressive symptoms in schizophrenia patients are associated with distinct morbidity and mortality. The objective of this study was to investigate the prevalence of depressive symptoms in a subgroup of chronic schizophrenia, Kraepelinian schizophrenia, and the association with severity of illness. Kraepelinian schizophrenia is characterised by a chronic, unremitting, severe course of illness and severe deterioration of functioning in social, work and self-care domains

Method. The Calgary Depression Scale for Schizophrenia (CDSS) and the Clinical Global Impression Severity (CGI-S) scale were administered to 113 patients who fulfilled the criteria of Kraepelinian schizophrenia.

Results. Sixty-eight males and 45 females participated in the study. Of this group, $17.7 \%$ scored 5 or more on the CDSS. The CGI-S scores indicated that almost half of the patients were moderately ill (i.e. a score of 4 on the CGI-S scale). Of the patients, 94 were receiving first-generation antipsychotic medication and 19 secondgeneration antipsychotic medication. Thirteen patients were also receiving antidepressant medication.

Conclusion. The findings of this study are consistent with current reports in the literature that depressive symptoms are not common in Kraepelinian schizophrenia, even though patients are moderately to severely ill in both symptom and functional domains.

One of the least understood but most common phenomena in schizophrenia are co-morbid mood disorders. ${ }^{1,2}$ Bleuler (cited by
Siris ${ }^{3}$ ) studied depressive phenomenona in schizophrenia as early as 1908. He suggested that the disease process might trigger mood symptoms in schizophrenia, while in other cases mood symptoms take the role of secondary symptoms.

Today there is still considerable symptom overlap between schizophrenia and mood disorders, and the relationship between depression and schizophrenia remains controversial. ${ }^{4}$ Many patients carry chart diagnoses of both disorders in the clinical setting. Some of the difficulty with the term 'depression' in schizophrenia may be attributed to ambiguity regarding whether the term refers to the particular emotion, i.e. feeling depressed, or to the syndrome of depression, consisting of a constellation of symptoms including a depressed feeling. Unfortunately the literature on depression in schizophrenia is often unclear with regard to whether the symptom or the syndrome of depression is involved. ${ }^{3}$

Proportions of patients presenting with depressive symptoms in schizophrenia range from a high of $75 \%$ to a low of $7 \%$. The modal rate of depression for all reports is given as $25 \%$. $^{3.5}$ Depressive symptoms in individuals with schizophrenia are associated with distinct morbidity and mortality, ${ }^{4-6}$ including a worse outcome and higher rates of relapse or re-hospitalisation. Schizophrenia patients with depression have more substancerelated problems and poorer social and family relationships, show a lower level of medication adherence and experience diminished general life satisfaction.

Furthermore, suicide terminates the lives of an estimated $10-15 \%$ of schizophrenia patients with depression; $40-50 \%$ of depressed patients with schizophrenia attempt suicide. ${ }^{7}$

Depression is common in people suffering from schizophrenia in all phases of the illness and may be a prodromal symptom, occurring in the year before the onset of the psychosis. ${ }^{4}$ Depression may be present during the first episode of schizophrenia, after a psychotic episode and during the chronic phase of schizophrenia. Depressive symptoms may also occur as a subjective reaction to the experience of psychotic decompensation. ${ }^{8}$

Nearly half of drug-naive patients in the first episode of schizophrenia suffer from depression. It has been hypothesised that depressive symptoms in the first episode may play a core part in the disease process, sharing the same underlying pathopsychological process of the acute illness. This idea is supported by the findings 
that depression is associated with an increased risk of transition to psychotic disorder, and that psychotic-like experiences reduce concurrently with an improvement in depression. ${ }^{9}$

Schizophrenia represents a heterogeneous patient population. Studying a distinct homogeneous subgroup therefore offers the advantage of reducing the influence of the heterogeneousness on the variability of prevalence of depression in schizophrenia.

Studies ${ }^{10,11}$ have reported that depressive symptoms are less frequent in schizophrenia patients in the chronic period than in the acute period. The prevalence of depressive symptoms is lower in patients suffering from one proposed subgroup of chronic schizophrenia, Kraepelinian schizophrenia, compared with published data on non-Kraepelinian chronic patients. ${ }^{11}$

Kraepelinian schizophrenia is characterised by a chronic course of illness and severe deterioration of functioning in social, work and self-care domains. The Kraepelinian subgroup of schizophrenic patients is defined as having been totally dependent on others for the provision of necessities such as food, clothing and shelter for at least the previous 5 years. ${ }^{12}$

The differences between Kraepelinian and non-Kraepelinian subtypes have been described by Roy et al. ${ }^{13}$ The Kraepelinian subtype is characterised by an unremitting and severe course and the non-Kraepelinian subtype by a remitting course and periods of self-care. The Kraepelinian group has more impairment on neuropsychological testing, more severe negative and positive symptoms, less severe depressive symptoms and relative nonresponsiveness to treatment with haloperidol.

Neuro-imaging studies have also been used to compare the two subgroups. Kraepelinian subtype patients were characterised by lower metabolic rates in the temporal lobe and cingulate gyrus and lower fronto/occipital ratios than non-Kraepelinian patients. Kraepelinian patients have greater left-sided structural brain abnormalities than non-Kraepelinian patients. ${ }^{14}$

Exploratory statistical probability mapping also revealed lower metabolic rates in the right striatum in Kraepelinian versus nonKraepelinian patients. Differences in age, symptom severity, or severity of involuntary movements could not explain these differences. ${ }^{14}$

\section{Objective}

The objective of this study was to investigate the prevalence of depressive symptoms, assessed using the Calgary Depression
Scale for Schizophrenia (CDSS), in a relatively homogeneous group of chronically institutionalised patients with Kraepelinian schizophrenia. The researchers used the CDSS because of its discriminate validity. The CDSS evaluates depressive symptoms independently from the disease phase in this subject population. In addition, the researchers used the Clinical Global Impression Severity (CGI-S) scale to investigate whether depressive symptoms were significantly associated with the severity of the illness.

\section{Method}

All hospitalised patients in the long-term wards of Weskoppies Hospital, Pretoria, who had a psychotic disorder were approached for recruitment. Patients provided written informed consent to their participation. The Research and Ethics Committee of the Faculty of Health Sciences, University of Pretoria, approved the study. Two of the authors (HE N, R S) had administered the CDSS and CGI-S scale after appropriate training in the use of these instruments. Eligible patients for this study had to have met the Diagnostic and Statistical Manual of Mental Disorders, 4th edition, text revision (DSM-IV-TR) $)^{15}$ criteria for residual schizophrenia. Further inclusion criteria were that patients had to have been continuously hospitalised and totally dependent on the institution for the provision of necessities such as food, shelter and clothing for the past 5 years. The following were exclusion criteria: (i) patients younger than 18 years; (ii) patients with a history of alcohol or other substance abuse or dependence in the preceding 6 months; (iii) evidence of a psychiatric disorder due to a general medical condition (iv) an unstable medical condition; and (v) DSM-IV-TR diagnosis of schizo-affective disorder. ${ }^{15}$

Scales often used to evaluate depression in schizophrenia are the Hamilton Depression Rating Scale ${ }^{16}$ (HDRS), the Montgomery Asperg Depression Rating Scale (MADRS) and the Beck Depression Inventory (BDI). These scales were not developed specifically to assess depression in patients with a diagnosis of schizophrenia. ${ }^{17,18-19}$ Other symptoms of schizophrenia, such as negative symptoms, may therefore affect the validity of these depression scales. For this reason Addington et al. ${ }^{20}$ developed the CDSS, which was derived from the HDRS and Present State Examination (PSE). ${ }^{21,22}$ Additional data were duration of illness, age, gender, marital status, antipsychotic and antidepressant medication received at the time of the study, and duration of hospitalisation. Statistical analyses comprised one-way frequency tables for all the variables and two-way frequency tables between selected pairs of variables, as well as Pearson correlations. 


\section{Results}

Demographic details on the patients are set out in Table I. The majority of patients who participated in this study were white, single males, most received typical antipsychotics, and in most cases the duration of their illness was more than 10 years. The mean age of the subjects was 49.2 years (standard deviation (SD) 11.09 years). The minimum age was 27 years and the maximum age 79 years. There were no significant correlations between depression and the duration of illness $(p=0.09)$, duration of hospitalisation ( $p=0.03)$, gender $(p=0.6)$ or marital status ( $p=0.8)$. There was a slightly higher proportion of patients suffering from depression among males (19.1\%) than females (15.5\%). The CDSS scores are set out in Table II. The majority of patients (93) scored $\leq 4 ; 20$ scored $\geq 5$. Analysis of the individual items showed guilty ideas of reference to be the most common, followed by pathological guilt, depression, observed depression, self-deprecation, hopelessness, early wakening, morning depression and suicide.

The CGI-S scores showed $49.56 \%$ of patients as being moderately ill. No significant associations were found between the severity of illness (CGI-S score) and the presence of depression ( $p=0.1)$.

\begin{tabular}{|c|c|c|}
\hline Characteristic & Total & $\begin{array}{l}\text { Proportion } \\
\text { of sample (\%) }\end{array}$ \\
\hline \multicolumn{3}{|l|}{ Duration of illness } \\
\hline $5-10$ yrs & 53 & 46.9 \\
\hline$>10 \mathrm{yrs}$ & 60 & 53.1 \\
\hline \multicolumn{3}{|c|}{ Duration of hospitalisation } \\
\hline $5-10 y r s$ & 68 & 60.2 \\
\hline$>10$ yrs & 45 & 39.8 \\
\hline \multicolumn{3}{|l|}{ Gender } \\
\hline Female & 45 & 39.8 \\
\hline Male & 68 & 60.2 \\
\hline Age (mean (SD)) & 49.2 & 11.1 \\
\hline \multicolumn{3}{|l|}{ Marital status } \\
\hline Single & 68 & 60.2 \\
\hline Married & 11 & 9.7 \\
\hline Widowed & 10 & 8.9 \\
\hline Separated & 1 & 0.9 \\
\hline Divorced & 23 & 20.4 \\
\hline \multicolumn{3}{|l|}{ Antipsychotics } \\
\hline Typical & 94 & 83.2 \\
\hline Second generation & 19 & 16.8 \\
\hline Antidepressants & 13 & 11.5 \\
\hline
\end{tabular}

\begin{tabular}{lcc}
$\begin{array}{l}\text { Table II. CDSS scores and item scores of patients with } \\
\text { Kraepelinian schizophrenia }(\boldsymbol{N}=113)\end{array}$ & $\begin{array}{c}\text { No. of } \\
\text { patients }\end{array}$ & $\begin{array}{c}\text { Proportion of } \\
\text { patients (\%) }\end{array}$ \\
\hline & & \\
\hline CDSS scores & 93 & 82.3 \\
$0-\leq 4$ & 20 & 17.7 \\
$\geq 5$ & & \\
Item of CDSS & 44 & 38.9 \\
Guilty ideas of reference & 41 & 36.3 \\
Pathological guilt & 39 & 34.5 \\
Depression & 32 & 28.3 \\
Observed depression & 29 & 25.7 \\
Self-deprecation & 23 & 20.4 \\
Hopelessness & 15 & 13.4 \\
Early wakening & 12 & 10.6 \\
Morning depression & 11 & 9.7 \\
Suicide & & \\
\hline
\end{tabular}

\section{Discussion}

In this study, less than a fifth of patients with Kraepelinian schizophrenia patients had a significantly high CDSS score $(\geq 5)$. Kilzieh et al. ${ }^{12}$ found that only $5 \%$ of their patients scored 16 or more on the HDRS. A difference in the thresholds of the two different scales for the presence of depression may be a plausible explanation for the different findings - a score of 16 on the HDRS seems at clinical face value to be a higher threshold than a 5 on the CDSS.

In a study by Rocca et al., ${ }^{23}$ male gender was associated with an increased severity of depressive symptoms. Our study also indicated that a slightly higher proportion of male patients than females suffered from depression.

Our research found no statistically significant association between severity of illness (measured by the CGI-S scale) and the presence of depression, which is consistent with previous studies. ${ }^{12,24}$

Liddle et al. ${ }^{24}$ suggest that depression may be related to the psychopathology of the subjective experience of schizophrenia in two ways, namely the 'psychological' and the 'neural mechanism'. According to the 'psychological mechanism', the subjective experience of deficits may be a predisposing condition for depression, which would arise as an understandable expression of the awareness of the loss of normal mental function. The distress associated with 'deficit awareness' is due to the insight of the practical constraints brought about by these deficits. Limitations of the study include the following: 
1. A comparison with a control group would have shed light on the differences in mood symptoms between Kraepelinian and non-Kraepelinian schizophrenia.

2. We assessed the CGIS scale, but did not include ratings of positive and negative symptoms. Future studies doing so could study the relationship between depression and the various schizophrenia symptoms in Kraepelinian schizophrenia.

\section{Conclusion}

This study confirmed results from previous studies that less than a fifth of patients with Kraepelinian schizophrenia suffer from depression, in spite of having moderate clinical global impairment. Further studies are needed that include correlation analyses between depression and positive and negative symptoms in both Kraepelinian and non-Kraepelinian schizophrenia.

\section{References}

1. Kilzieh N, Kennedy A Wood AE, Raskind M Tapp A Depression in schizophrenia: From diagnosis to prognosis. Directions in Psychiatry 2004; 24(1): 69-78.

2. Kennedy A, Rosengren K, Kilzieh N, Wood AE, Tapp A. Does depression predict quality of life in outpatients with schizophrenia spectrum disorders? Biol Psychiatry 2004; 55(8S): 73S

3. Siris SG. Depression in schizophrenia; perspective in the era of 'atypical' antipsychotic agents. Am J Psychiatry 2000; 157: 1379-1389.

4. Connolly J. Depression, suicide and schizophrenia. Journal of Crisis Intervention and Suicide Prevention 2003; 24(3): 91-92.

5. Micallef J, Fakra E, Blin O. Use of antidepressant drugs in schizophrenic patients with depression. Encephale 2006; 32: 263-269.

6. Limosin F, Loze JY, Philippe A, Casadebaig F, Rouillon F. Ten-year prospective follow up study of the mortality by suicide in schizophrenic patients. Schizophr Res 2007 94: $23-28$
7. Hausmann A, Fleischaker WW. Differential diagnosis of depressed mood in schizophrenia; a diagnostic algorithm based on review. Acta Psychiatr Scand 2002; 106: 83-96.

8. Andersen SW, Trana PV. The course of depressive symptoms in predicting relapse in schizophrenia: a double-blind, randomized comparison of olanzapine and risperidone. Arch Gen Psychiatry 1999; 46: 365-373.

9. Yung AR, Buckby JA, Cotton SM, et al. Psychotic-like experiences in nonpsychotic help-seekers: Associations with distress, depression and disability. Schizophr Bull 2005; doi: 10.1093/schbul/sbj018 10

10. Bandelow B, Müller P, Gaebel W, et al. Depressive syndromes in schizophrenic patients after discharge from hospital. J Eur Arch Psychiatry Clin Neurosci 1990; 240(2): $113-120$.

1 1. Lancon C, Acquier P, Reine G, Barnard D, Addington D. Relationship between depression and psychotic symptoms of schizophrenia during an acute episode and stable period. Schizophr Res 200 1; 47: 135-140.

12. Kilzieh N, Wood AE, Erdmann J, Rashkind M, Tapp A. Depression in Kraepelinian schizophrenia. Comp Psychiatry 2003; 44(1): 1-6.

13. Roy MC, Bassard A, Rene L, et al. Kraepelinian and non Kraepelinian schizophrenia: replication and extension of previous findings. Schizophr Res 2001; 49(suppl): 28.

14. Buchsbaum M. Kraepelinian and non-Kraepelinian schizophrenia subgroup differences in cerebral metabolic rate. Schizophr Res 2002; 55: 25-40.

15. American Psychiatric Association. Diagnostic and Statistical Manual of Mental Disorders, 4th ed., text revision. Washington, DC: American Psychiatric Association, 2000: 316.

16. Hamilton MA. Rating scale used for depression. J Neurol Neurosurg Psychiatry 1960 23: $56-62$

17. Kim SW, Kim SJ, Yoon BH, et al. Diagnostic validity of assessment scales for depression in patients with schizophrenia. Psychiatry Res 2006; 144: 57-63.

18. Mortimer AM. Symptoms rating scales and outcome. Br J Psychiatry 2007; 191: 7 14

19. Kontaxakis VP, Havaki-Kontaxaki BJ, Stamouli SS, Margariti MM, Collias CT, Christodoulou GN. Comparison of four scales measuring depression in schizophrenic patients. Eur Psychiatry 2000; 15: 274-277.

20. Addington D, Addington J, Schissel B. A depression rating scale for schizophrenia. Schizophr Res 1990; 3:247-25

21. Lancon C, Aquier P, Reine G, Bernard D, Toumi M. Study of concurrent validity of the Calgary Depression Scale (CDSS). J Affect Disord 2000; 58: 107-1 15.

22. Müller MJ, Müller KM, Fellgiebel A. Detection of depression in acute schizophrenia: sensitivity and specificity of 2 standard observer rating scales (Brief Communication. Can J Psychiatry 2006: 51: 387-392

23. Rocca P, Silvia B, Calvarias $P$, et al. Depressive and negative symptoms in schizophrenia: different effects on clinical features. Compr Psychiatry 2005; 46 : 304-310

24. Liddle PF, Barnes TRE, Curson DA, Patel M. Depression and the experience of psychological deficits in schizophrenia. Acta Psychiatr Scand 2007; 88: 243-247. 